\title{
Os discursos e as metáforas na análise da propensão à participação: um estudo em um banco privatizado*
}

\author{
Márcia Prezotti Palassi** \\ Alexandre de Pádua Carrieri*** \\ Alfredo Rodriques Leite-da-Silva**** \\ Thiago Duarte Pimentel*****
}

SUMÁRIO: 1. Introdução; 2. A privatização e o movimento antiprivatização; 3. O processo de participação; 4. A análise do discurso e de suas metáforas; 5. As articulações para a participação no movimento antiprivatização do Banespa; 6. Considerações finais.

SuMmary: 1. Introduction; 2. Privatization and the anti-privatization movement; 3 . The participation process; 4 . Analysis of the discourse and its metaphors; 5. The articulations for participating in Banespa's antiprivatization movement; 6 . Final remarks.

Palavras-Chave : discursos; metáforas; participação; antiprivatização.

KEY WORDS: discourses; metaphors; participation; anti-privatization.

\footnotetext{
* Artigo recebido em dez. 2006 e aceito em mar. 2007.

** Professora do Programa de Pós-Graduação em Administração (PPGADM) da Ufes. Doutora em psicologia (psicologia social) pela PUC-SP. Endereço: Av. Fernando Ferrari, 514 - Goiabeiras - CEP 29075-010, Vitória, ES, Brasil. E-mail: mprezotti@hotmail.com.

$* * *$ Professor e coordenador do Núcleo de Estudos Organizacionais e Simbolismos (Neos) da UFMG. Doutor em administração pela UFMG. Endereço: Rua Curitiba, 832, sala 1.202 - Centro - CEP 30170-120, Belo Horizonte, MG, Brasil. E-mail: alexandre@cepead.face.ufmg.br. $* * * *$ Pesquisador do Núcleo de Estudos Organizacionais e Simbolismos (Neos) da UFMG. Doutorando em administração pelo Cepead/Face/UFMG e mestre em administração pela Ufes. Endereço: Rua Curitiba, 832, sala 1.202 - Centro - CEP 30170-120, Belo Horizonte, MG, Brasil. E-mail: arls@cepead.face.ufmg.br.

***** Pesquisador do Núcleo de Estudos Organizacionais e Simbolismos (Neos) da UFMG. Mestrando em administração pela UFMG e graduado em turismo. Endereço: Rua Curitiba, 832, sala 1.202 - Centro - CEP 30170-120, Belo Horizonte, MG, Brasil. E-mail: xtdp@cepead.face.ufmg.br.
} 
Este artigo apresenta as contribuições da análise dos discursos e de suas metáforas como um caminho para investigar e compreender as articulações que envolvem os processos de participação nas organizações. Uma discussão teórica sobre privatização e antiprivatização, participação, análise do discurso e metáforas norteou uma pesquisa empírica qualitativa para evidenciar as articulações para a participação dos trabalhadores de uma organização bancária no Brasil, o Banespa, inserida num processo de privatização. A coleta de dados foi realizada por meio de 45 entrevistas e da seleção de documentos do movimento antiprivatização. Como técnica de análise dos dados adotou-se a análise do discurso (AD) (Fiorin, 2001) e os dados foram tratados com base no modelo das sete dimensões de participação de Sandoval (1994). Como resultado, os discursos e as metáforas confirmaram que a falta de propostas coletivas viáveis para enfrentar a privatização levou a alternativas individuais, o que se consolidou, após a privatização, na falta de espaços propícios para a participação em torno de outras questões.

\section{Discourses and metaphors in the analysis of the propensity to participate: a study in a privatized bank}

This paper evidences the contributions of the discourses analysis and of their metaphors as a means of investigating and to understanding the articulations that involve the participation processes in organizations. A theoretical discussion about privatization and anti-privatization, participation, discourse analysis and metaphors has guided a qualitative empiric research to evidence the articulations for employee participation in a Brazilian banking organization (Banespa) undergoing a privatization process. Data collection was accomplished through 45 interviews and documents of the anti-privatization movement. The data was analyzed through discourse analysis (Fiorin, 2001) and treated based in Sandoval's (1994) model of the seven dimensions of participation. As a result, the discourses and the metaphors confirmed that the lack of viable collective proposals to face privatization lead to individual alternatives, which were consolidated, after the privatization, in the lack of favorable spaces for participation in the discussion of other issues.

\section{Introdução}

Este artigo parte do entendimento de que por meio de uma abordagem de análise do discurso (AD), com foco nas metáforas, é possível investigar as articulações referentes à participação que nelas se manifestam. $O$ argumento se baseia nas propostas de Zanotto (1998), para quem as metáforas podem ser consideradas um fenômeno discursivo de valor cognitivo e indeterminado, 
podendo revelar os universos simbólicos construídos pelos atores sociais e organizacionais. Portanto, configura-se como um caminho para a compreensão do contexto simbólico que envolve as articulações das diferentes maneiras de participação.

Essa dimensão simbólica se materializa por meio do e no discurso, sobretudo por meio de metáforas, em virtude de elas constituírem a principal forma de organização do pensamento e da comunicação humana (Jackobson, 1988). Devido à capacidade de acesso à dimensão simbólica, o discurso e as metáforas nele manifestadas levam o pesquisador à compreensão de construções sociais referentes às racionalizações, às representações, às normas e aos valores. Tais elementos conformam e legitimam determinadas formas de pensar e de interagir com a realidade, o que Berger e Luckmann (2004) identificam como a construção de determinadas visões de mundo.

Neste artigo, ao se optar por estudar as metáforas veiculadas pelos atores sociais, em suas articulações para a participação social, espera-se corroborar com a busca por conhecimentos que contribuam para a compreensão dos processos que envolvem essas articulações. Para tanto, a discussão proposta parte do seguinte problema de pesquisa: como a análise dos discursos e das metáforas contribui para a investigação e compreensão das articulações que envolvem os processos de participação nas organizações?

Para legitimar em evidências empíricas a discussão teórica referente ao problema proposto, desenvolveu-se uma pesquisa de campo que adota a análise dos discursos e de suas metáforas. A intenção é destacar as contribuições dessas escolhas metodológicas no estudo das articulações para a participação no Banespa, neste caso num contexto de privatização, com características específicas referentes a esse processo, a serem consideradas na análise.

O artigo está organizado da seguinte maneira: a primeira parte do texto é esta introdução; a segunda parte destaca alguns aspectos contextuais dos processos de privatização e os movimentos antiprivatização; a terceira parte trata do processo de participação; a quarta parte discute o estudo das metáforas, em conjunto com a $\mathrm{AD}$, como uma alternativa teórico-metodológica para uma abordagem empírica das questões referentes à participação e seu contexto de inserção, no caso o movimento antiprivatização; a quinta parte apresenta um estudo de caso para inserir elementos empíricos na discussão; por fim, são apresentadas as considerações finais do artigo.

\section{A privatização e o movimento antiprivatização}

As especificidades de contextos organizacionais, envolvidos por processos de privatização, se concretizam a partir dos conflitos entre os objetivos financeiros 
e os riscos envolvidos (Domberger e Piggott, 1994). Em conjunto com o objetivo comumente declarado, da eliminação da intervenção pública e da melhoria da eficiência da economia, surge uma retórica voltada para algo mais complexo, um processo de regulação de interesses (Costas, 1995). Ou seja, a disseminação de processos com o potencial de reconfigurar relações de interesses econômicos em níveis locais, nacionais e internacionais, por meio de políticas privatizadoras que podem se dividir em três grandes categorias (Domberger e Piggott, 1994; Cainzos, 1994):

\ transferência de ativos do setor público ao privado, em geral mediante sua venda;

V desregulação ou liberalização dos monopólios legais (com ou sem venda de ativos), com ênfase particular em eliminar as restrições de entrada;

> concessão de franquias, contratações externas ou subcontratações para a oferta de bens e serviços comerciais concedidos a empresas do setor privado.

A discussão sobre a implementação dessas políticas extrapola o debate técnico, pois a defesa da empresa privada diante da empresa pública, ou viceversa, está submetida a projetos ideológicos, de maneira que, em muitos casos, tem-se utilizado a apelação à eficiência como argumento para defender posições definidas a priori, em favor ou contra a mudança de titularidade da empresa pública (Páramo, 1995). Nos estudos em que as posições a priori são evitadas, a ênfase recai na problematização do fenômeno caso a caso, de acordo com o contexto envolvido. Assim, o ponto crítico da análise gira em torno do processo de gestão e suas implicações, sendo a forma de propriedade (pública ou privada) apenas mais um componente contextual (Fernández, 1995).

Inseridos nessas diferentes posições ao estudar a privatização, os trabalhos que se voltam para as reações dos trabalhadores após a privatização indicam como aspecto comum a emergência de sentimentos de medo, de agressão e de desintegração da ação. Ao mesmo tempo, surgem posições em uma atitude positiva com relação ao processo de privatização. Neste último caso o processo é defendido como uma tendência moderna que permitirá à empresa funcionar melhor (Balawajder e Popiolek, 1993).

Entre esses posicionamentos, o que comumente é assumido pelos trabalhadores fica evidente pelos estudos que indicam suas reações típicas ao processo (Oliva, 2000): greves reivindicando o bloqueio da privatização e a disseminação de boatos e ruídos na comunicação. Os mesmos estudos demonstram que a maneira como o processo de privatização é conduzido mais aterroriza do que promove apoio ao trabalhador (Oliva, 2000). Durante o processo 
esse terror se concretiza nas estratégias para a redução de custos, como os planos de demissão voluntária ou incentivada, que sinalizam a inserção da empresa na lógica privada da concorrência e da busca por clientes e rentabilidade (Wetzel, 2000). Tanto os remanescentes como os ex-trabalhadores da empresa manifestam medo e sofrimento diante de uma série de inseguranças que se apresentam em relação ao mercado de trabalho, ao emprego, à renda, à representação e formas de contratação do trabalho (Tolfo et al., 2001).

Para o movimento antiprivatização a alternativa para lidar com todas essas conseqüências é a mobilização, em níveis locais, nacionais e internacionais, por meio de reuniões, debates, listas de discussão na internet, criação de observatórios, manifestações e outras ações políticas voltadas para a defesa da gestão pública. Uma de suas principais propostas é que a sociedade assuma sua responsabilidade na decisão, controle e gestão dos assuntos públicos em vez de privatizá-los. Para isso é necessária a participação do indivíduo em alguma ação coletiva, o que tende a variar desde um nível máximo de participação e compromisso até uma curiosidade não-obstacularizadora (González, 1998).

\section{O processo de participação}

González (1998) discute a existência de diversos níveis de participação e associa o nível máximo ao compromisso que surge inserido num grupo social. Esse entendimento leva ao reconhecimento da relação entre participação e inserção no grupo social. Neste artigo ele levou à adoção do seguinte conceito de participação: um envolvimento no qual pertencer a um grupo significa ter e ser parte de algo, além de tomar parte em algo (Sánchez, 2000).

A relevância desse entendimento pode ser ilustrada pelas articulações existentes nos movimentos sociais, com destaque para as cinco formas típicas (Grau e Ibarra, 2001:8-9):

V organiza-se de forma participativa;

v tenta mobilizar a sociedade para participar na resolução dos problemas que o caracterizam, incentivando as pessoas a atuarem nos espaços institucionalizados, onde se tomam as decisões políticas, assim como nos espaços econômicos, culturais e políticos;

จ tenta fazer com que o poder político os considere na tomada de decisão;

$\checkmark$ mobiliza as pessoas para atuar na gestão dos assuntos nos quais a sua vida está envolvida; 
V desenvolve um discurso de participação voltado à socialização política, ao tentar fazer a sociedade ver a participação não só como um instrumento de mobilização, mas como um valor em si mesmo, "que aposta por uma condição mais humana, mais integral, por uma condição humana que nega a divisão”.

Um aspecto a se destacar nos movimentos sociais é a observação de uma redução na participação sindical, que se dá tanto por problemas internos do movimento sindical quanto pelas dificuldades impostas pela transição de uma sociedade industrial a uma sociedade de risco global. Nesta última o emprego dá lugar ao trabalho, estabelecendo uma relação na qual o capital é global e o trabalho é local (Castells, 2002), afetando também o comprometimento no trabalho. Nesse processo a individualização se relaciona com as articulações pelas quais a participação sindical e política se reduz, ao mesmo tempo em que grupos de indivíduos têm levado para a agenda social os temas de um mundo ameaçado, na qual a esfera global, fora do nível de atuação prática cotidiana da maioria dos indivíduos, sobrepõe-se à local. Os limites do político passam a diluir-se, dando lugar, de forma simultânea, ao que Beck (2002) chama de subpolítica, referindo-se à política não-institucional como campo de atuação de diferentes formas de comportamento coletivo, como modas de curta duração, furores, lutas, greves, desastres, pânicos, movimentos sociais, revoluções etc.

Deve-se ressaltar que o termo "sub" parece inadequado, pois pode passar uma conotação pejorativa, mas a intenção do autor é destacar as implicações dessa subpolítica e não diminuí-la. Para ele o problema central da era da globalização é o dilema democrático, sob pena de caminharmos para uma sociedade mundial tecnocrata. Para evitar esse destino o autor propõe a busca por uma democracia cosmopolita, como uma utopia necessária, da qual a aproximação depende do reconhecimento de que nas culturas da sociedade contemporânea a individualização e a diversidade são componentes cada vez mais presentes.

A necessidade do desenvolvimento de uma consciência de solidariedade cosmopolita e da instituição da democracia, defendida por Beck (2002), remete à discussão da associação entre consciência e ideologia. Conforme Sandoval (2001), a consciência política sofre influência da ideologia na medida em que a formação da consciência se dá pelos aspectos identitários e pelas crenças construídas socialmente na sociedade. Uma construção que ocorre ao mesmo tempo em que tais crenças são internalizadas pelos indivíduos, de acordo com suas percepções sobre o contexto social.

Nesse processo a consciência se apresenta como a capacidade dos indivíduos de dar-se conta do que acontece em seu meio e/ou do que pensam de si 
mesmos, tendo como função organizar a enormidade de informações que os rodeiam (Madruga e Ríos, 1998) e a "ideologia (ou 'ideológicas', em sentido amplo) como as práticas e construções sociais dominantes, histórica e culturalmente situadas, que identificam, orientam e controlam uma comunidade" (Cronick e García, 1998:247).

Ao tentar envolver a sociedade na defesa da causa que propõe, o movimento antiprivatização, com características de um movimento social e aqui considerado como tal, estabelece em sua dinâmica uma aproximação com essas definições. Portanto, é possível caracterizar o movimento como um fenômeno também ideológico, em vez de somente econômico ou técnico. Nesse cenário a investigação da predisposição à participação no movimento envolve o estudo da consciência política.

O estudo da consciência política é uma escolha que se justifica pela variabilidade de aspectos e símbolos utilizados em jogos particulares de idéias em vários foros públicos. Dentro dessa variedade, neste artigo, o foco recai sobre os símbolos presentes em metáforas, frases de propaganda, imagens, atrações morais, valores, ideologias, convicções, conforme Gamson (1992), elementos para a interpretação do mundo e as condições nas quais um assunto público é discutido. Para o autor, a maior compreensão da relação da vida privada com as demandas e ofertas de participação depende da identificação de elementos que podem favorecer ou inibir a participação. Ele se refere a aspectos como o sentimento de injustiça, a agência e a identidade, em contrapartida aos custos pessoais e oportunidade política. A partir da identificação desses elementos deve-se explicar como alguns podem se sobressair e levar à adesão da defesa de algo em que se acredita.

A ênfase na consciência política baseia uma abordagem na qual as pessoas são consideradas menos passivas do que podem parecer, pois negociam com as mensagens da mídia de forma complexa, em variações de assuntos e argumentos que evidenciam buracos de conhecimento e confusões (Gamson, 1992). Ao se observar os grupos sociais é possível ter contato com suas identidades e verificar como eles emergem e entram em ação (Melucci, 1995). Nessa ótica, a participação das pessoas num grupo social é reconhecida como um processo que envolve uma diversidade de fatores, tais como a identidade de valor, a obrigação moral, o recrutamento promovido pelos movimentos sociais, o temor de sentimentos de culpabilidade e vergonha decorrentes de sua falta de participação perante os grupos de interesse (Gecas, apud Stryker, Owens e White, 2000). Entre esses fatores há de se destacar a participação relacionada com a identificação (Brewer e Silver, 2000), associada à identidade coletiva e à identidade social. 
Ao se concordar com o entendimento de Klandermans e Weerd (2000), o sentido de identidade coletiva adotado neste artigo é o de cognições compartilhadas por membros de um único grupo, e o de identidade social é o de cognições de um indivíduo em relação à sociedade ou com mais grupos. A identificação se relaciona com ambos, sendo definida como a parte da identidade coletiva no nível individual que a vincula à identidade social. A "identificação de grupo é uma condição necessária para a participação de protesto (...) [pois,] não só ensina a preparação para a participação, mas também faz as pessoas levarem a cabo as intenções delas" (Klandermans e Weerd, 2000:86). A permeabilidade dos limites de grupo também estimula a participação, pois os indivíduos podem se identificar com uma causa sem se identificar com grupos ou organizações que trabalham para a causa. Analisar a identificação implica examinar as convicções de um indivíduo, sentimentos, compromissos com o grupo, uso de símbolos, participação em rituais e assim por diante.

A conseqüência psicológica da identificação grupal "envolve a transformação da sensação de ego do indivíduo de 'eu' para o coletivo 'nós'. Em efeito, os limites do ego são redefinidos para incluir outros da categoria pertinente. Essa transformação tem aspectos cognitivos, motivacionais e manifestações afetivas" (Brewer e Silver, 2000:160). Por outro lado, quando a identificação é muito forte tende a levar ao hedonismo, enquanto exigências muito altas de submissão ao grupo podem provocar o desejo de saída do grupo.

Quando a identificação social é comprometida, o bem-estar grupal se torna uma parte do cálculo racional pelo qual o indivíduo avalia os custos e benefícios de ações intencionais e resultados em potencial (Brewer e Silver, 2000). Para Melucci (2001), as contradições e incompatibilidades também podem revelar descompassos entre expectativas e recompensas em relação ao investimento realizado na ação. Conforme o autor, as sociedades complexas têm seu contexto marcado pelo processo de "individuação", ou seja, a atribuição individual do sentido de agir. Nesse contexto a não-participação dá às pessoas a liberdade de não-pertencimento, seja como "possibilidade de reduzir-se à identidade constituída para produzir-se novamente", seja como "possibilidade de rejeitar ou modificar as condições dadas pela representação" (Melucci, 2001:138). O conhecimento gerado no processo de construção do "nós" concede aos participantes a consciência sobre a ação (Melucci, 2001), ainda que esta não se desenvolva espontaneamente (Klandermans e Weerd, 2000).

Essa visão da participação como um processo permeado por relações simbólicas e materiais vai de encontro à proposta de Sandoval (1994). Para o autor, a análise dos significados da expressão verbal dos indivíduos deve ser realizada combinando os elementos "atitudinais" com os dados do contexto de onde emergem. Segundo Sandoval (1994), essa abordagem exige a compreen- 
são das experiências de classe do indivíduo. Para desenvolver a abordagem o autor propõe sete dimensões distintas que se articulam de forma dinâmica, cujo jogo de reflexões busca explicar os motivos que levam as pessoas a optar pela ação individual ou coletiva: a identidade coletiva; as convicções de sociedade, valores e expectativas; os sentimentos de interesses coletivos e adversários; a eficácia política; os sentimentos de injustiça; a vontade para agir coletivamente; e as metas e ações do movimento social.

Essas dimensões formam a consciência política que, com freqüência, tem sua transformação na interrupção da rotina diária e que ao ser analisada requer o exame de "como se estrutura a maneira de pensar do indivíduo" (Sandoval, 1994:61). De maneira convergente a este último argumento o movimento antiprivatização pode ser considerado como um elemento de ruptura do cotidiano. Por ser um processo polêmico, a avaliação dos trabalhadores sobre esse processo poderá revelar adversários e interesses antagônicos, que podem ser enquadrados no que Sandoval (1994) identifica como os sentimentos do indivíduo com relação aos seus interesses simbólicos e materiais. Segundo o autor, esses interesses se apresentam em oposição aos de outros grupos, de maneira a configurar as divergências de interesses e a visualizar adversários coletivos em uma sociedade.

A complexa cadeia de interesses e de adversários presentes no movimento antiprivatização o aproxima das preocupações de Sandoval (1994), o que justifica a adoção do seu modelo das sete dimensões, como modelo analítico deste estudo. Outro ponto defendido pelo autor e também aqui assumido é a ênfase na relevância do componente simbólico no processo de participação. Um entendimento convergente com as propostas de Gamson (1992), nas quais as metáforas se destacam como um dos elementos com o potencial de interpretação de relações que envolvem o processo de articulação para a participação. Indo ao encontro dos dois autores, neste artigo adotou-se o estudo dos discursos e de suas metáforas, como o caminho para o estudo das articulações para a participação e o aproveitamento do potencial do modelo analítico de Sandoval (1994).

\section{A análise do discurso e de suas metáforas}

Neste artigo assume-se o entendimento de que "o discurso são as combinações de elementos lingüísticos (frases ou conjuntos constituídos de muitas frases), usadas pelos falantes com o propósito de exprimir seus pensamentos, de falar do mundo exterior ou de seu mundo interior, de agir sobre o mundo" (Fiorin, 2001:11). Em conjunto com esses elementos lingüísticos estão as metáforas 
que, conforme Grant e Oswick (1996a), oferecem contribuições específicas para revelar o cotidiano organizacional. Os autores se baseiam no entendimento de que as organizações podem ser vistas como o resultado de múltiplos discursos permeados por metáforas que refletem o cotidiano. Esses discursos são construídos pelos diversos atores sociais, ao longo de suas histórias de vida e da história da organização.

Para o desenvolvimento de uma abordagem de análise com base nas metáforas, Grant e Oswick (1996b) propõem questões teóricas e metodológicas que norteiam a abordagem empírica deste artigo, quais sejam:

$\checkmark$ a necessidade de pesquisa aplicada sobre metáforas na teoria e análise organizacional;

$\checkmark$ o uso das metáforas como base de pesquisa;

$\checkmark$ uma maior exploração da ironia e da metonímia em suas variações típicas: a sinédoque - uso das relações semânticas quantitativas, tais como o gênero pela espécie, a parte pelo todo e o singular pelo plural; a metalepse uso das relações entre causa e conseqüência; e a antonomásia - uso das relações entre nomes e qualificativos, conceitos estreitamente relacionados ao pensamento metafórico.

As metáforas ajudam a compreender a construção dos discursos e as maneiras pelas quais eles fornecem significados aos atores sociais, evidenciando relações no cotidiano dos trabalhadores, inclusive suas articulações para o processo de participação. Essa visão vai ao encontro das propostas de Berger e Luckmann (2004), com enfoque na linguagem e na ação cotidiana. Nessa abordagem a linguagem é tida como elemento central na construção social da realidade e das identidades, do comportamento, das estruturas sociais e das organizações (Westwood e Linstead, 2001). A interpretação intersubjetiva é considerada a maneira pela qual se deve compreender: a interdependência da linguagem cotidiana na interação social; e a construção dos significados que ela manifesta a partir de sua relação contextual.

$\mathrm{O}$ entendimento sobre as metáforas adotado neste artigo rompe com o modelo objetivista baseado na teoria aristotélica, em que a metáfora era vista apenas como uma figura de linguagem ou retórica com função de ornamentar o discurso. Na abordagem adotada a metáfora é considerada uma dimensão cognitiva, constitutiva da linguagem e do pensamento da realidade cotidiana (Zanotto, 1998), um produto social manifestado pelo indivíduo.

Jakobson (1988) defende que a construção de sentido, na interpretação e composição da linguagem metafórica e metonímica, varia nas manifesta- 
ções: de similaridade, efetivada nas operações de seleção e substituição na linguagem; e de contigüidade, formada pela faculdade de combinação e contexto. Baseada nessas proposições, Zanotto (1998) apresenta como processo de interpretação da construção de sentido metafórico a "relação ontológica" entre dois domínios do conhecimento: o "processo analítico", que estabelece relações entre diferentes domínios conceituais; e o "prévio conhecimento de mundo" dos sujeitos sociais, ancorado em suas visões de mundo. Esse entendimento foi assumido neste artigo e norteia os procedimentos de análise das metáforas observadas nos discursos organizacionais. Para operacionalizar essa análise recorreu-se, como orienta Zanotto (1998), a um método qualitativo de análise, no caso o da análise do discurso (AD) (Fiorin, 2001).

$\mathrm{A} \mathrm{AD}$ fornece um quadro conceitual que permite a análise da produção oral e escrita de discursos, enfatizando, sobretudo, o contexto social de produção dos discursos e de seus significados socialmente construídos (Carrieri, Pimentel e Cabral, 2005). Um método de análise dos discursos, aqui defendido, é a análise dos temas e figuras expressados por meio das estratégias de persuasão discursivas (Faria e Linhares, 1993): a criação de personagens; a seleção lexical; o silenciamento; e a relação entre conteúdos explícitos e implícitos.

Diversos estudos organizacionais com base na $\mathrm{AD}$ evidenciam o uso das estratégias mencionadas. Barry e Elmes (1997) destacam o uso da construção de personagens para expor ou ocultar figuras de acordo com os temas organizacionais envolvidos. Watson (1995) trata da definição dos vocabulários dos grupos por meio da seleção lexical, o que permite a eles delimitar e expor temas e figuras em seu cotidiano. Sobre o silenciamento, Mumby e Stohl (1991) mencionam a importância da dialética na relação do dito com o nãodito, pois evidencia o que é hegemonicamente mantido, à medida que certas experiências são sistematicamente incluídas, lembradas, e outras não.

A última estratégia, a relação entre conteúdos explícitos e implícitos, baseia-se na articulação entre o que é colocado de maneira explícita pelo locutor, sobre o que ele assume total responsabilidade, e aquilo que pode ou não ser assumido pelo destinatário, o implícito. Por sua vez, o implícito se subdivide em dois tipos básicos: os implícitos pressupostos, partes do sentido do enunciado que obrigam o destinatário a assumir algo ao concordar com o conteúdo explícito (Ducrot, 1987); e os implícitos subentendidos, que oferecem liberdade de construção da imagem, por parte do destinatário da fala, a partir do contexto (Ducrot, 1987).

Essa distinção fica mais clara ao se observar a afirmação: "eu comprei uma empresa, os juros subiram e fiquei na miséria". Se o destinatário aceitar o tema explícito de que o locutor "ficou na miséria", também tem que aceitar o tema implícito pressuposto de que "antes ele não era miserável", não há alter- 
nativa. Ao mesmo tempo, o trecho pode remeter ao tema implícito subentendido de que "os juros altos levam qualquer empresário para a miséria". Entretanto, nesse caso, o destinatário tem espaço para ignorar esse subentendido, tudo dependerá do contexto da fala entre ambos. Se o locutor argumenta contra acusações de que era incompetente, defendendo-se com o tema implícito subentendido de que "os juros altos levam qualquer empresário para a miséria", mesmo com o destinatário concordando que os juros subiram, dificultando a atividade empresarial, ele ainda pode discordar da justificativa para o insucesso do locutor, evocando, por exemplo, o tema: "os juros altos dificultam as coisas, mas levam apenas os empresários incompetentes para a miséria". Portanto, emergiu um implícito subentendido que se opõe à argumentação do locutor, só acessível a partir da observação do contexto de produção dos discursos.

Ao observar o uso das estratégias mencionadas é possível evidenciar temas e figuras evocados pelos atores organizacionais e organizá-los em percursos semânticos. "O conceito de percurso semântico engloba os conceitos greimasianos de percurso temático e percurso figurativo, por serem ambos de revestimentos - mais abstratos ou mais concretos, respectivamente - de estruturas narrativas" (Faria, 2001:33). Fiorin (2001:82) esclarece os conceitos greimasianos (Greimas e Courtés, 1979) ao descrever o percurso temático como "um encadeamento de temas que podem ser resumidos num tema mais geral" e o percurso figurativo como " um encadeamento de figuras que manifesta um dado tema". Do encontro do percurso temático com o percurso figurativo tem-se o percurso semântico. Ele é composto pelos temas e pelas figuras que manifestam esses temas. Esses percursos semânticos são grandes categorias de análise, que permitem agrupar os elementos discursivos de acordo com as convergências e oposições em relação às quais os diversos discursos veiculados se articulam.

A partir da composição dos percursos semânticos e/ou de subconjuntos internos aos percursos semânticos é possível evidenciar as oposições entre temas e figuras e os diferentes discursos que eles compõem. Dessa maneira, no seu conjunto, a análise dos discursos contribui para a compreensão da construção de narrativas, tanto organizacionais quanto institucionais, um caminho para o entendimento das mudanças físicas e simbólicas ocorridas no contexto em estudo.

Ao se propor o uso de uma abordagem lingüística para o estudo das articulações que envolvem os processos de participação nas organizações busca-se acessar, por meio dos discursos, o processo de construção social nas organizações. Parte-se do reconhecimento de que os discursos e as metáforas nele contidas envolvem as articulações no cotidiano social e organizacional, constituindo, ao mesmo tempo, um caminho para a compreensão dessas articulações, como se discute a seguir. 


\section{As articulações para a participação no movimento antiprivatização do Banespa}

\section{Aspectos metodológicos}

Na abordagem empírica deste estudo procedeu-se a uma investigação em um banco no estado de São Paulo - o Banespa. Foi considerada a história dessa organização antes, durante e após a privatização. A intensidade desse processo, as transformações geradas por ele e seus impactos sobre os atores sociais remeteram ao interesse em focar essa organização. As dificuldades para os atores conviverem em organizações inseridas nessa mudança radical, com perda de suas referências históricas e conflitos de interesses, abrem espaço para a participação assumir a condição de um mecanismo de apoio aos trabalhadores, durante e após o processo de privatização. Por meio dela se constroem bases de suporte mútuo, tanto de afetividade, marcada por aspectos como a amizade e o apoio psíquico, quanto de recursos específicos, caracterizada pela oferta de condições mais concretas, como o acesso às informações, aos equipamentos, à infra-estrutura, aos recursos financeiros. Em conjunto essas bases tendem a compor condições mais propícias para a defesa de determinados interesses mútuos de um grupo social, dentro ou fora de uma organização.

A relevância da escolha por focar a participação dos atores inseridos na organização em questão se reforça pelas evidências de profundas alterações na percepção dos trabalhadores sobre a própria organização. Percepções que revelaram a desconstrução e reconstrução de formas de ver e se relacionar com a organização, em processos de racionalização e de institucionalização manifestados na incorporação, no uso e no desenvolvimento de léxicos próprios, de acordo com as distintas visões de mundo construídas contextualmente.

Para a obtenção dos discursos do grupo social que envolve os trabalhadores do Banespa foram realizadas, entre dezembro de 2000 e outubro de 2001, entrevistas semi-estruturadas, baseadas apenas em um roteiro, com 17 sindicalistas e 28 trabalhadores, além da coleta de documentos do movimento antiprivatização. Para preservar a identidade dos respondentes, os fragmentos de seus depoimentos são identificados no artigo por meio do termo sindicalista ou trabalhador, seguido de uma numeração. Após a coleta os dados foram analisados por meio da $\mathrm{AD}$, com foco no uso do discurso metafórico. Ao observar as estratégias discursivas foi possível identificar figuras e temas dos discursos e os percursos semânticos compostos por eles. A partir desses temas buscou-se compreender as articulações que envolvem o processo de participação no movimento antiprivatização do Banespa, com base nas sete dimensões propostas por Sandoval (2004). Cada fragmento dos dados coletados apresen- 
tados neste artigo tem os termos ou os trechos citados na análise marcados por meio de um destaque gráfico. Esses fragmentos foram transcritos na íntegra, sem modificações para a língua culta, portanto, alguns mantêm construções consideradas gramaticalmente incorretas, mas necessárias para a análise dos discursos dos respondentes.

\section{Breve histórico do Banespa ${ }^{1}$}

Em 1909 foi fundado o Banco de Crédito Hipotecário e Agrícola do Estado de São Paulo, controlado por franceses. Em 1926 o Tesouro paulista e o Instituto do Café adquiriram 98\% do capital do banco, sendo chamado de Banco do Estado de São Paulo (Banespa).

Anos mais tarde, em 30 de novembro de 1994, ocorreu a intervenção do Banco Central (Bacen) no Banespa, sob alegação de que ele estava "quebrado", o que era explicado na mídia como resultado de falhas em questões estratégicas comerciais, mercadológicas e tecnológicas e da ingerência política por parte de governos estaduais irresponsáveis. Mas para os que se opunham ao Bacen a divulgação das informações era uma estratégia do governo federal a favor da privatização (Biondi, 2001), havendo apenas certo consenso sobre o uso político inadequado do Banespa pelo governo estadual, traduzido em dívidas do estado com o banco.

Em 1995 o governo federal liberou recursos para o banco viabilizar financiamentos e o Bacen apresentou a intenção de liquidá-lo, o que foi rejeitado pelo governo do estado. Neste ano se iniciou a redução do quadro de 39,3 mil funcionários para 22,5 mil, em cinco anos.

Em 1997, após um acordo com a União para o pagamento de parte das dívidas do estado e um refinanciamento do restante em 30 anos, o governo estadual repassou empresas estatais paulistas à União e o banco foi federalizado. Logo em seguida, em 1998, o Bacen contratou avaliadores para definirem o preço para a privatização. À medida que a privatização se evidenciou surgiram diversas ações judiciais, paralisações e grandes manifestações de protesto contra a privatização (Biondi, 2001), com a participação de produtores rurais, cidadãos, promotores do Ministério Público, mais de 300 prefeitos, câmaras de municípios do interior de São Paulo e de outros estados e autoridades em geral.

\footnotetext{
${ }^{1}$ As informações apresentadas no breve histórico foram obtidas da pesquisa, por meio do cruzamento de depoimentos dos vários respondentes e de dados oriundos de diversos documentos.
} 
Dias antes do leilão foi realizada uma grande greve dos banespianos, mas o leilão foi realizado em 20 de novembro de 2000 , tendo como vencedor o Banco Santander Central Hispano (BSCH) que adquiriu o Banespa por $\mathrm{R} \$ 7,05$ bilhões, $281,02 \%$ de ágio sobre o preço mínimo. O Banespa era um dos maiores bancos estatais brasileiros, com patrimônio líquido de $\mathrm{R} \$ 4,4$ bilhões, lucro líquido de $\mathrm{R} \$ 324,1$ milhões, ativos na ordem de $\mathrm{R} \$ 28,9$ bilhões, 572 agências, 771 postos de atendimento, 3 milhões e 80 mil clientes.

Após a privatização iniciou-se a "política de reestruturação", com a substituição de funcionários, contratação de estagiários, terceirização de serviços, implantação de automação, ampliação de metas, e desligamento de 11 mil funcionários por meio de um programa de demissão voluntária. Esses fatos e o melhor tratamento do Santander aos funcionários espanhóis na fusão com o Banco Central Hispano nortearam as organizações representativas dos funcionários a recomporem a movimentação social, em oposição à política do Santander.

Em junho de 2001 ocorreu a Semana Mundial de Lutas no Santander, as entidades representativas realizaram protestos e encaminharam documentos à Organização Internacional do Trabalho (OIT) denunciando o excesso de jornada de trabalho, o desrespeito às leis trabalhistas e a discriminação que o grupo promove na América Latina. Essa movimentação teve continuidade e, em agosto de 2001, ocorreu o XV Congresso Nacional dos Banespianos, aprovando propostas para defender os direitos dos trabalhadores, as estratégias para a campanha salarial de 2001 e a renegociação do acordo coletivo, compondo as movimentações do primeiro ano da privatização no Banespa, locus da investigação deste artigo.

\section{A compreensão das articulações para a participação por meio dos discursos}

$\mathrm{O}$ início do processo de $\mathrm{AD}$ partiu de uma postura na qual se reconhece que um mesmo respondente veicula em seus discursos elementos de mais de um percurso semântico, inclusive que se opõem entre si, numa aparente incoerência. Isso ocorre pois os elementos manifestados fazem parte do seu universo de formação discursiva (Foucault, 1972) e são usados por ele em suas estratégias de persuasão. Ou seja, o enunciador usa elementos de um percurso para se articular discursivamente sobre o outro. Com essa ênfase no universo de formação discursiva do grupo social, a análise vai além de um fato ou personagem isolado.

Nessa abordagem os fatos narrados em si, de maneira isolada, não são o foco da análise, não existe preocupação em identificar quem "mente" ou fala a 
"verdade" sobre determinados fatos, pois em qualquer uma das duas opções os respondentes têm que lançar mão do seu universo discursivo, revelando-o. Esse universo é o foco da análise e para alcançá-lo, ou pelo menos parte dele, busca-se evidenciar os elementos dos percursos semânticos, expressos à medida que os respondentes procuram defender seus argumentos.

Esse nível de análise permite acessar o contexto de inserção social do grupo investigado, contribuindo para a compreensão das articulações do grupo social em torno do processo de participação. No caso do Banespa, a partir da $\mathrm{AD}$, foi possível evidenciar temas e figuras que indicaram oposições discursivas configuradas em dois principais percursos semânticos, aqui identificados como: o da participação e o da não-participação.

Do percurso semântico da participação em torno da luta antiprivatização destacaram-se os seguintes temas: a mobilização; a superação das diferenças dos grupos sociais; as vitórias a partir da mobilização antiprivatização; a mobilização como garantia para alcançar reivindicações; a necessidade de outras maneiras de mobilizar e participar; e a participação apoiada pela empresa. Cada um desses temas foi demarcado por estratégias discursivas manifestadas em conjunto com um grande número de metáforas nas falas dos respondentes. Na impossibilidade de apresentar aqui a análise de todas as falas selecionou-se para cada tema pelo menos um fragmento discursivo a ele relacionado.

O tema da mobilização, em torno da luta antiprivatização, é demarcado nos fragmentos 1 e 2 por meio da estratégia de escolha lexical do termo "contra a privatização" (fragmento 1) e o uso das metáforas nos trechos "ninguém mediu esforços" (fragmento 1) e "entrou na luta, entrou na briga" (fragmento 2), bem como pela estratégia de criação de personagens, no fragmento 1: "segundo escalão pra baixo", "funcionários", "as entidades"; e no fragmento 2 : "Ninguém". Este último termo é uma escolha lexical que remete a um personagem por meio do qual fica para o próprio ouvinte, de modo implícito subentendido, a definição de quem ele entende que será incluído na mobilização. Uma estratégia de persuasão que busca legitimidade ao dar espaço para o outro inserir sua interpretação na construção do discurso.

1. (...) do segundo escalão pra baixo, que são funcionários da empresa, de carreira, deram total apoio à luta que as entidades de representação moveram, contra a privatização (...) os funcionários de carreira como um todo, ele entrou na luta, entrou na briga e a avaliação foi positiva.

(Sindicalista 1) 
2. Ninguém mediu esforços (...) Cada um deu a sua cota de participação do que podia dar.

(Trabalhador 1)

Esse entendimento é reforçado em outros fragmentos que associam temas adicionais, convergentes com a idéia de participação, mobilização e antiprivatização, tais como:

3. nós [do sindicato] sempre tivemos divergências internas dentro da própria organização sindical, mas nesse processo de privatização nós conseguimos criar uma unificação. Mesmo entre as correntes, entre as forças que trabalham na organização do Banespa, a gente sempre conseguiu se manter unificado (...) foram propostas que saíram a partir do movimento sindical, ou do sindicato ou da Afubesp [Associação dos Funcionários do Banco do Estado de São Paulo] ou essas entidades conjuntas a partir do Comando Nacional Banespa.

(Sindicalista 2)

A escolha lexical no trecho "nesse processo de privatização" e o uso do discurso metafórico no trecho "conseguimos criar uma unificação" reforçam o tema anterior e remetem ao tema implícito da superação das diferenças dos grupos sociais (trabalhadores, sindicatos e associações) em torno da agenda da privatização. Esse tema emerge das estratégias de persuasão discursivas destacadas no tema anterior, em conjunto com as escolhas lexicais no trecho "sempre tivemos divergências" em oposição ao trecho "sempre conseguiu se manter unificado", quando se refere de maneira implícita subentendida às articulações referentes ao movimento antiprivatização. $O$ tema também fica evidente na criação de personagens: "nós", no sentido implícito subentendido de os membros do sindicato, "movimento sindical", "sindicato" e "Afubesp", personagens inseridos naquela "unificação" e que a demarcam para o ouvinte.

Associado aos dois temas anteriores emergiu o de que houve vitórias a partir da mobilização antiprivatização, como fica explícito no fragmento 4 , com destaque para as escolhas lexicais nos trechos "não perdemos nenhum direito, durante todos esses anos" e "Nós fomos muito vitoriosos e eles acuaram", este último com o uso de metáforas que reforçam a idéia de que houve uma articulação e uma disputa entre dois lados. No caso, o lado que se beneficiou é demarcado como o personagem "nós", referindo-se aos funcionários do Banespa, grupo ao qual o respondente pertence.

4. Por mais que eles tentassem, nós não perdemos nenhum direito, durante todos esses anos e não deixamos de ter reajuste, a cada negociação. 
(...) Nós fomos muito vitoriosos e eles acuaram (...) Nós não ficamos numa luta corporativa pelo salário e pelo emprego, mas fizemos muito bem isso também (...) e estamos com esses direitos até hoje, mesmo com o banco privatizado.

(Trabalhador 2)

No fragmento anterior ao assumir explicitamente que o banco foi privatizado, demarcado pelo termo "banco privatizado", surge o seguinte questionamento: como eles são vitoriosos se o movimento antiprivatização falhou? A resposta a tal questionamento fica silenciada nos fragmentos, mas nos leva a uma inferência de que associadas às vitórias ocorreram também derrotas por parte do movimento.

A ênfase nas "vitórias", mesmo conhecendo as derrotas, envolve também os argumentos referentes à continuidade da participação, que norteiam o tema: a mobilização como garantia para alcançar reivindicações. No fragmento 5 o personagem "nós", referindo-se implicitamente, de modo pressuposto, aos banespianos, é colocado numa condição de manutenção da mobilização alcançada no processo antiprivatização. Já a derrota é demarcada implicitamente, de modo subentendido, no trecho "mesmo com a privatização" que é posto como uma realidade, dentro da qual aquela manutenção da mobilização deve ocorrer. Por fim, a possibilidade de novas vitórias surge de maneira implícita subentendida, a partir das relações de conteúdos "manter" e "nossas reivindicações", a partir dos quais se extrai uma possível relação causal, onde o processo de manutenção das reivindicações ao longo do tempo levaria às possíveis vitórias do movimento no futuro.

5. nós nos devemos manter unidos mesmo com a privatização pra conseguir as nossas reivindicações né.

(Sindicalista 1)

Essas reivindicações passam a tomar o lugar das ações antiprivatização, colocadas em segundo plano após a privatização, mas a questão não é colocada de lado, pois é assumida para nortear o tema da necessidade de outras maneiras de mobilizar e participar, em um banco privado. Ele surge de maneira implícita no fragmento 6 . O uso do discurso metafórico nos trechos "O momento hoje é outro" e "É uma participação mais... light". O primeiro indica uma mudança que o trecho "para entrar no banco privatizado" já demarca como a privatização do banco estatal. O segundo indica que essa mudança teve como conseqüência maneiras de participação menos intensas, como fica evidente pelo uso do termo light, referindo-se a uma intensidade mais suave 
no modo de participação dos atores sociais no movimento antiprivatização. Tal mudança exige também outras formas de mobilizar os trabalhadores, como fica explícito nos trechos "a mobilização que a gente precisa" e "são outros tipos de atividade".

6. O momento hoje é outro. A organização e a mobilização que a gente precisa ter para entrar no banco privatizado ela se dá através de assembléia, de seminários, são outros tipos de atividade. E o banespiano tem correspondido. (...) Só, que claro, que nem tão exposto né, como talvez fosse melhor né. É uma participação mais... light.

(Trabalhador 3)

Uma vez inserido no contexto privatizado a participação ganha também um contorno empresarial, no sentido de surgir o tema: a participação apoiada pela empresa. No fragmento 7 esse tema surge demarcado de maneira implícita pelo uso da metáfora no trecho "visto com bons olhos pela empresa pessoas que participam da sua comunidade" no sentido de que aquele seria um comportamento esperado pela empresa, avaliado por ela como correto. A existência dessa avaliação da empresa é reforçada no fim do fragmento nas escolhas lexicais do trecho "visão do que é ou não é bom para a empresa", ou seja, existiria um tipo de participação que a empresa considera bom, a participação na comunidade foi colocada como um exemplo explícito desse tipo, mas fica silenciado nesse fragmento qual não seria bom. Em outros fragmentos discursivos a participação sindical surge como um exemplo explícito do tipo de participação a que a empresa se opõe, portanto, de maneira implícita subentendida ela se encaixaria nesse silenciamento, sendo avaliada como ruim.

7. Já vi algumas palestras do diretor de recursos humanos (...) ele deixou entender que é visto com bons olhos pela empresa pessoas que participam da sua comunidade. Enfim, esse negócio é um pouco difundido hoje em dia, que isso mostra que tem companheirismo, tem espírito de equipe, de não sei o que. Um pouco dessa visão do que é ou não é bom para a empresa.

(Trabalhador 4)

Esses seis temas se destacam na composição do percurso semântico da participação, mas, em oposição a eles, outros seis temas surgiram articulando o percurso semântico da não-participação. Dentro desse percurso semântico os temas que se destacaram foram: a ineficácia da mobilização; os interesses conflitivos entre os trabalhadores; o medo de represálias contra a 
participação; a falta de tempo para participar; o individualismo; a desmobilização do banespiano pós-privatização.

O tema da ineficácia da mobilização se traduz pelo entendimento de que participar pela antiprivatização não dá resultado, surgindo de maneira explícita no fragmento 8 demarcado pelas escolhas lexicais nos trechos "participei contra o processo de privatização" e "Não que isso fosse dar algum resultado"; e no fragmento 9 pelas escolhas lexicais nos trechos "não vou continuar participando" e "vi que não ia ter resultado". Nos dois fragmentos a participação é relacionada a um resultado esperado não alcançado. No fragmento 9 também fica explícito que a participação exige esforço, demarcado na escolha lexical do termo "cansativo" no trecho "ia ser tão cansativo", deixando de modo implícito subentendido que ela não se sustenta, pois a privatização seria inexorável. Tal constatação levaria os trabalhadores a se desmotivarem, como demarca o termo "não vou continuar".

8. Eu participei contra o processo de privatização (...) Não que isso fosse dar algum resultado.

(Trabalhador 5)

9. Olha nos dois, três primeiros dias eu participei, depois eu senti que esse negócio ia continuar, ia ser tão cansativo que eu cheguei aqui dentro e falei "eu não vou continuar participando". Ia ser cansativo e eu vi que não ia ter resultado [impedir a privatização].

(Trabalhador 6)

No fragmento 8 fica explícito que a participação ocorre mesmo sem a expectativa de resultado positivo, já no fragmento 9 a participação foi interrompida, mas em ambos fica demarcada a falta de expectativa quanto aos resultados. A ênfase nos resultados surge ainda na discussão sobre as relações de interesses, a partir das quais diferentes expectativas no tocante a determinados resultados a serem alcançados remetem ao tema: os interesses conflitivos entre os trabalhadores. No fragmento 10 ele surge de maneira implícita nas escolhas lexicais dos termos "funcionalismo", "babaca", "preocupação" e "com o bolso", na qual o funcionário do Banespa além de ser qualificado de maneira pejorativa por meio do termo "babaca" que remete à idéia de tolo, associa essa característica ao fato de ele priorizar retornos financeiros, como demarca a metáfora do "bolso", que se oporia a uma questão mais ampla e importante - a da participação social.

No fragmento 11 esse tema é reforçado, mas agora com um corte num grupo específico dentro do banco, os funcionários de carreira que possuem cargos nos níveis mais altos da hierarquia, tendo seus interesses influenciados 
por essa inserção profissional e por sua expectativa quanto à aposentadoria. Isso é demarcado pelas escolhas lexicais com o uso do discurso metafórico nos trechos "operações que nasceram no banco", "profissionais de carreira, que se omitiram, porque deviam o seu cargo" e "aí eles conseguiriam se aposentar". Nos trechos os termos "banco", "deviam", "cargos" e "aposentar" posicionam a personagem coletiva "funcionalismo" na mencionada rede de interesses. Nessa rede determinados "profissionais de carreira" que "deviam o seu cargo" se afastam do movimento antiprivatização para serem beneficiados. A atuação esperada era a de que esses funcionários contribuíssem para o movimento, mas ela não se concretiza, o que destaca certo conflito de interesses, como fica implícito subentendido nas escolhas lexicais do trecho "poderiam passar informação, nem isso estavam fazendo".

10. É um funcionalismo extremamente babaca [o do Banespa] (...) a preocupação dele é com o bolso dele, como está sendo agora. Só. Não há uma preocupação social. (...) Sabe, por isso que eu não lamento. (...) O Brasil está desse jeito, porque enfim, é o povo que tem. Não participa.

(Trabalhador 7)

11. Todas as operações que nasceram no banco, elas nasceram com o conhecimento dos profissionais de carreira, que se omitiram, porque deviam o seu cargo a uma indicação política, porque... por vários motivos. (...) Os profissionais de carreira, apesar de que não tinham muito poder, mas poderiam passar informação, nem isso estavam fazendo. (...) Estavam torcendo para durar mais um ano a intervenção porque aí eles conseguiriam se aposentar.

(Trabalhador 8)

Associado a esse tema surge outro, no qual o conflito se dá no tocante aos interesses da empresa e às represálias que ela pode impor ao funcionário, caso esses interesses sejam contrariados, remetendo ao tema: o medo de represálias contra a participação. No fragmento 12 ele é demarcado quando se observa a indicação temporal de duas épocas distintas, a partir da escolha do verbo ser, no pretérito imperfeito "era", no sentido de que antes existia uma condição diferente da atual. Essa condição anterior é associada a uma liberdade maior de participação por meio das escolhas lexicais que associam a personagem "elas" (indicando as pessoas que trabalham no Banespa), aos termos "manifestações", "inventarem coisas", "virem com cartaz" e "demonstrar uma alegoria". De maneira implícita subentendida o fragmento se refere ao período anterior à privatização. No fragmento 13 a dificuldade e o medo do segundo período (pós-privatização) ficam claros ao serem evidenciados nas escolhas 
lexicais com o discurso metafórico no trecho "se você quiser crescer, você não vai", ou seja, quem quer progredir em sua carreira não deve participar do que foi identificado de maneira explícita no próprio fragmento como "entidades" e "representação de funcionários".

12. era muito comum nas manifestações, elas [as pessoas que trabalham no Banespa] inventarem coisas, virem com cartaz, entendeu. Era o dia do vermelho contra não sei o quê, as pessoas vinham com um coração, as pessoas mesmo inventavam umas coisas assim pra demonstrar uma alegoria.

(Sindicalista 3)

13. No Banespa, assim, quem quis participar de entidades, de representação de funcionários, nunca foi cerceado, teve a carreira prejudicada no banco. Banco privado é diferente (...) se você quiser crescer, você não vai (...).

(Trabalhador 9)

Deve ficar claro que, na prática, essas represálias podem existir ou não, mas apenas a veiculação desse medo nos discursos já as insere no cotidiano das pessoas como uma justificativa para a não-participação. Uma outra justificativa surge no tema da falta de tempo para participar. Esse tema surge de maneira explícita no fragmento 14 ao indicar a falta de tempo, nas escolhas lexicais no trecho "eu só não tenho tempo", e a associa à participação, nas escolhas lexicais no trecho "A gente tem que participar de alguma coisa". No caso, a estratégia de persuasão discursiva destaca essa falta de tempo e a coloca acima da vontade da pessoa, subordinando a suposta vontade de participar.

14. Se a gente não se filiar a nada é como se a gente tivesse morto. A gente tem que participar de alguma coisa, eu só não tenho tempo, mas eu gostaria muito de participar de tudo (...).

(Trabalhador 10)

Na mesma linha dos dois temas anteriores, no tocante às justificativas para a não-participação, surge o tema do individualismo, segundo o qual cada um deve se ater ao seu trabalho. No fragmento 15 esse tema é demarcado implicitamente de maneira pressuposta nas escolhas lexicais com o discurso metafórico no trecho "eu nunca fui participativa lá no sindicato, eu sempre fiquei na minha" e "eles têm o trabalho deles, eu tenho outro". No primeiro trecho o personagem "eu" tem seu comportamento de não-participação exposto e reforçado pelos advérbios "nunca" em oposição à participação e "sempre" 
em conformidade com a não-participação. No segundo trecho o personagem "eu" é associado à não-participação e o personagem "eles" à participação, destacando o papel de cada um pelos termos "eles têm" e "eu tenho outro".

15. Eu vou continuar na mesma coisa que eu sempre fui, eu nunca fui participativa lá no sindicato, eu sempre fiquei na minha. Eu espero que eles façam pela gente, eles têm o trabalho deles, eu tenho outro trabalho.

(Trabalhador 11)

Essa justificativa para a não-participação, assim como as outras presentes nos dois temas anteriores remetem ao tema da desmobilização do banespiano pós-privatização. No fragmento 16 esse tema é reforçado nas escolhas lexicais com o discurso metafórico nos trechos "ou o banco compra as pessoas com o salário" "ou as pessoas não têm a mesma garra, a mesma participação". Nos trechos ficam evidentes duas alternativas, como demarca de maneira explícita o uso da conjunção alternativa "ou". No primeiro trecho o personagem "banco" é colocado de maneira explícita como o responsável pela efetivação da racionalidade instrumental, ligada à questão financeira, como demarca de maneira implícita pressuposta o termo "compra as pessoas". Fica implícito subentendido que caso essa "compra" se concretize ela seria responsável pela desmobilização das "pessoas", o outro personagem destacado explicitamente no trecho. A desmobilização surge de maneira implícita subentendida no segundo trecho do mesmo fragmento, demarcada pelo uso dos termos "não têm", "garra" e "participação". Mas, como demarca a conjunção alternativa "ou", caso o "banco" não tenha efetivado sua "compra" a responsabilidade de desmobilizar as "pessoas" iria para outro personagem: as próprias "pessoas".

No segundo trecho, "ou as pessoas não têm a mesma garra, a mesma participação", o termo "pessoas" demarca um personagem que ao mesmo tempo se desmobiliza e é responsável por essa desmobilização. Nesse trecho o termo "garra", no sentido de intenso vigor, é associado à "participação" e ambos colocados como algo que existia antes, mas que agora mudou, como demarca o termo "não têm a mesma". Essa desmobilização tem sua responsabilidade transferida para as "pessoas" na medida em que a conjunção alternativa "ou" indica que a elas resta essa responsabilidade caso não seja do personagem "banco". Nesse sentido, de maneira implícita subentendida, tanto o "banco" quando as "pessoas" se aproximam no tocante a uma sobreposição da racionalidade instrumental, ligada à questão financeira, em relação a uma racionalidade substantiva, ligada à participação, sendo os interesses dos grupos sociais e organizacionais ditados pela questão da eficiência financeira e 
a busca por interesses individuais, como já destacado no tema do individualismo.

16. (...) ou o banco compra as pessoas com o salário ou as pessoas não têm a mesma garra, a mesma participação.

(Sindicalista 4)

Esse último tema e os outros que compõem os percursos semânticos da participação e da não-participação evidenciam articulações que envolvem o processo de participação no Banespa ao serem analisados com base nas sete dimensões de Sandoval (1994): a identidade coletiva; as convicções de sociedade, valores e expectativas; os sentimentos de interesses coletivos e adversários; a eficácia política; os sentimentos de injustiça; a vontade para agir coletivamente; e as metas e ações do movimento social.

No tocante à identidade coletiva os temas indicam um compartilhamento cognitivo em relação à oposição à privatização. Há certa fragmentação, pois alguns temas indicam o reconhecimento da privatização como algo inexorável e, também, como um processo que não seria contra os interesses específicos de alguns trabalhadores. A primeira questão se posiciona de maneira mais propícia para a participação, mas as outras duas estão mais associadas à não-participação, já que o inexorável é apenas algo a se aceitar e a ênfase em interesses específicos de alguns trabalhadores indica um isolamento.

Os temas indicam ainda que após a privatização ocorre uma mudança nesse compartilhamento, pois se dissemina o entendimento de que agora se trata de um contexto diferente, de "banco privado", exigindo a mudança de comportamento, inclusive em relação à participação e à mobilização. A imbricação dessa dimensão com outra, referente às convicções de sociedade, valores e expectativas permite vislumbrar que qualquer uma das três posições destacadas (a luta pela antiprivatização, a omissão ou o foco em interesses pessoais) tem legitimidade em relação à sociedade. Isso pode ser explicado pelo fato de existirem diferentes convicções, valores e expectativas presentes na sociedade contemporânea, compondo configurações possíveis de serem convergentes com cada uma das posições.

O convívio das diferentes configurações pode ser ilustrado nos argumentos manifestados por grupos distintos da sociedade ao discutirem aspectos do setor público, tais como: a defesa da estabilidade do servidor público no emprego, para proteger o patrimônio e os interesses públicos, bem como o próprio servidor contra as pressões e mudanças políticas; as críticas que questionam a própria motivação dos servidores públicos no sentido do interesse público, em virtude de possuírem a estabilidade. Os grupos inseridos nessa 
última argumentação acabam por se aproximar de questões como a competitividade privada, a empregabilidade como faceta do desenvolvimento pessoal e a redução da máquina pública como uma meta. Tanto a oposição à ingerência política, base do primeiro argumento, quanto os benefícios da lógica da competição privada, base do segundo, são questões presentes na sociedade e defendidas, muitas vezes, de maneira quase dogmática. Portanto, ambas permitem que os grupos busquem e encontrem certo espaço na sociedade para defenderem a coerência de cada um de seus argumentos.

Neste artigo esse convívio ficou claro na ênfase dada a diferentes interesses, inseridos na dimensão referente aos sentimentos de interesses coletivos e adversários. Há no Banespa uma nítida oposição entre dois interesses: a privatização e a antiprivatização. Mas enquanto os interesses coletivos da antiprivatização se situam entre os trabalhadores, os adversários estão fora, sendo identificados como as empresas e as instâncias do poder público interessadas na privatização, aqui se configura uma condição propícia à participação. Por outro lado, aqueles entre os trabalhadores que não se alinham ao movimento antiprivatização, por omissão ou por defender seus interesses específicos, carecem de um sentimento de interesse adversário, pois eles não são o foco da oposição daquele grupo anterior (antiprivatização), voltado para "fora" do banco, nem tampouco do grupo que defende a privatização. Portanto, no tocante a essa dimensão os trabalhadores não alinhados com a antiprivatização se inserem numa condição menos propícia à participação em torno de suas posições.

Após a privatização essa polarização se altera, a oposição entre privatização e antiprivatização dá espaço a uma aceitação da privatização e surge a oposição entre os interesses empresariais inseridos no banco privatizado e os interesses dos trabalhadores que buscam manter direitos conquistados anteriormente. Mas os temas indicam que nesse momento, pós-privatização, os sentimentos de interesses coletivos em torno dessa nova polarização são abalados pela própria derrota da mobilização antiprivatização. Dissemina-se certo ceticismo sobre a consecução desses interesses, indicando menos propensão à participação associada à percepção das pessoas sobre a eficácia política.

A dimensão referente à eficácia política tenderia a indicar plena propensão à participação caso o Banespa não tivesse sido privatizado, pois a conclusão da privatização remeteu os temas a um cenário de que para cada "vitória" destacada nos temas se seguiu uma derrota também evidenciada nos temas. Entretanto, a questão da eficácia política envolve temas que indicam "vitórias" associadas não apenas à antiprivatização, mas, também, à manutenção de 
direitos anteriores à privatização. Apesar disso, com a empresa privatizada, permeada pelo ceticismo sobre o futuro, a eficácia política é questionada. A propensão à participação se reduz como indicam os temas que remetem às justificativas para a não-participação, como a "falta de tempo" e o "medo de represálias". Os temas também se mostraram diretamente associados com os sentimentos de injustiça, que, por outro lado, indicariam uma condição propícia à participação, principalmente antes do processo de privatização se efetivar.

A dimensão referente aos sentimentos de injustiça se apresenta nos temas voltados para a antiprivatização como um eixo em torno do qual muitos argumentos articulam a mobilização e a luta coletiva. Nesse sentido ao se observar os temas que tratam do medo e das represálias, observa-se uma condição propícia à participação. Entretanto, após a privatização, a imbricação dessa dimensão com as outras reforça a necessidade de tomar "precauções", pois os temas indicam as injustiças percebidas como algo que terá relação com o seu comportamento dentro da "nova empresa privatizada", não como algo inevitável do ponto de vista pessoal e, por isso, lógico de exigir como única alternativa à mobilização. Esse último argumento se insere na discussão da competitividade e do desenvolvimento pessoal como presentes na contemporaneidade nas convicções de sociedade, valores e expectativas, ou seja, dissemina-se o discurso de que cada um deve cuidar apenas de "seu trabalho".

O conjunto das dimensões discutidas até aqui permite observar que na dimensão referente à vontade para agir coletivamente existem impulsos mais intensos na direção do agir coletivo no período antiprivatização do que após sua concretização. Após a privatização os temas indicam apenas a busca por novas formas sindicais de mobilizar e a demanda por parte do banco, agora privado, para incentivar o tipo de participação social que ele apóia. Nos dois casos os temas não indicam a vontade para a ação coletiva por parte dos trabalhadores, mas apenas o registro dessas alternativas, relacionadas à participação inserida no novo cenário de empresa privatizada. Nos temas sobre o período anterior à privatização, a vontade para a mobilização surge, comumente, em conjunto com o registro das alternativas para a participação, o que remete à última dimensão de Sandoval (1994), as metas e ações do movimento social.

No período anterior à privatização, a dimensão das metas e ações do movimento social girava em torno do objetivo específico de barrar a privatização a qualquer custo, com desenvolvimento de ações nas esferas jurídicas, político-partidárias, mobilização pública e coletiva, por meio de protestos, greves e divulgação de informações por meio da mídia. Após a privatização, os temas indicam a aceitação de uma nova agenda, típica nas relações 
empregatícias, voltadas para o salário e demais benefícios, e de novas maneiras de mobilizar, não mais envolvendo aquelas esferas, mas apenas o trabalhador isoladamente, o que, como visto nos temas é colocado como um desafio exigindo alternativas a serem buscadas.

Baseado na análise das sete dimensões de Sandoval (1994) há num primeiro momento, anterior à privatização, uma maior propensão à participação, que se reduz num segundo momento após a privatização. Tal processo se deu por meio de uma série de articulações que envolvem tanto a face concreta das relações cotidianas, como a demissão ou punição de um funcionário, quanto a face simbólica, como a interpretação e a disseminação de que aquilo vai ocorrer com todos os que se mobilizarem em desacordo com os interesses da empresa. Ao permitir acessar essas duas faces, presentes nas metáforas e nos discursos dos trabalhadores, a $\mathrm{AD}$ ofereceu os elementos necessários para se analisar essas articulações sob a ótica do modelo de Sandoval (1994), o que possibilitou uma compreensão aprofundada do processo que envolve os diferentes níveis de participação no caso do Banespa.

\section{Considerações finais}

A discussão teórica inicialmente desenvolvida evidenciou as contribuições do estudo dos discursos e das metáforas como um caminho para investigar e compreender as articulações que envolvem os processos de participação nas organizações. Esse objetivo proposto foi alcançado pelo confronto teórico das potencialidades da análise das metáforas e dos discursos em lidarem, simultaneamente, com as dimensões concretas e simbólicas que permeiam o processo de participação. A partir dessa contribuição teórica foi possível desenvolver o estudo empírico sobre o processo de participação no Banespa.

No caso, os dois percursos semânticos, o da participação e o da nãoparticipação, acabam se relacionando diretamente com o processo de privatização, com diferentes elementos referentes aos dois momentos, um anterior e outro posterior à privatização. Os dois percursos semânticos coexistem em ambos os momentos, fazendo parte do universo discursivo dos trabalhadores, mas no primeiro momento há o predomínio no discurso dominante do percurso semântico da participação, enquanto no segundo momento há um predomínio no discurso dominante do percurso semântico da não-participação.

Pode-se observar que o movimento antiprivatização criou um cenário propício para a participação do banespianos. Isso está relacionado a uma imbricação de elementos que se configuraram de maneira favorável a essa participação: uma identidade coletiva, uma percepção de acolhida por parte 
da sociedade, um sentimento de interesses convergentes, a eficácia política das ações em curso, o sentimento de injustiça, a vontade de agir, as metas e ações do movimento antiprivatização. Entretanto, em nenhum momento observou-se plena homogeneidade na configuração desses elementos, existiam articulações que indicavam uma consciência individualista, mas como indica a análise dos percursos semânticos, essa consciência só se dissemina mais intensamente entre os trabalhadores à medida que a privatização se concretiza, de modo "inexorável", levando à desmobilização em torno do movimento antiprivatização e certa decepção por parte dos trabalhadores.

Nesse segundo momento, confirmaram-se as propostas de Sandoval (2001), para quem a falta de propostas persuasivas coletivas viáveis para enfrentamento contribui para a adoção de alternativas individuais, a fim de se proteger das ameaças econômicas, gerando a passividade por parte dos trabalhadores. Essa constatação no caso do Banespa oferece subsídios para impulsionar a busca por alternativas viáveis, que devem considerar não apenas o fato concreto da empresa agora ser privada, mas as construções simbólicas que demarcam esse contexto como inapropriado à participação. Tais construções se configuraram aqui como um obstáculo a se mediar para tornar o cenário novamente propício para a participação. Aqui surge a contribuição deste artigo para o campo, assim como no caso do Banespa, propõe-se o uso em outros estudos da análise dos discursos e de suas metáforas como um caminho para se aproximar simultaneamente das faces concretas e simbólicas que contribuem ou prejudicam a articulação para a participação, contribuindo para a compreensão e gestão do processo.

\section{Referências bibliográficas}

BALAWAJDER, K.; POPIOLEK, K. Why people dislike the privatization of their work places? Polish Psychological Bulletin, v. 24, n. 1, p. 15-24, 1993.

BARRY, D.; ELMES, M. Strategy retold: toward a narrative view of strategic discourse. Academy of Management Journal, Amherst, v. 2, p. 429-452, 1997.

BECK, U. La sociedad del riesgo global. Madrid: Siglo XXI, 2002.

BERGER, P.; LUCKMANN, T. A construção social da realidade: tratado de sociologia do conhecimento. 24. ed. Petrópolis: Vozes, 2004.

BIONDI, A. O Brasil privatizado: um balanço do desmonte do Estado. São Paulo: Fundação Perseu Abramo, 2001. 
BREWER, M. B.; SILVER, M. D. Group distinctiveness, social identification and collective mobilization. In: STRYKER, S.; OWENS, T.; WHITE, R. Self, identity, and social movements. Minneapolis: University of Minnesota Press, 2000.

CAINZOS, J. J. F. Privatización: solución o filosofia económica? Revista Hacienda Publica Española, n. 128, p. 177-188, 1994.

CARRIERI, A. de P.; PIMENTEL, T. D.; CABRAL, A. C. de A. O discurso e sua análise no enfoque foucaultiano da formação discursiva: um método de pesquisa nos estudos organizacionais. Gestão.Org, Recife, v. 3, n. 2, p. 111-124, 2005.

CASTELLS, Manuel. A sociedade em rede. 6. ed. São Paulo: Paz e Terra, 2002.

COSTAS, A. Desregulación y privatización en la economia europea actual: motivaciones, resultados y enseñanzas. Revista Economistas, n. 63, p. 54-63, 1995.

CRONICK, K.; GARCÍA, J. A. Ideología, ética y compromiso en psicología comunitária. In: GONZÁLEZ, A. M. Psicologia comunitária. Fundamentos y aplicaciones. Madrid: Editorial Síntesis, 1998.

DOMBERGER, S.; PIGGOTT, J. Políticas privatizadoras y empresa pública: una visión panorámica. Revista Hacienda Pública Española, n. 128, p. 219-236, 1994.

DUCROT, O. O dizer e o dito. Campinas: Pontes, 1987.

FARIA, A. A. M. Interdiscurso e intradiscurso: da teoria à metodologia. In: MENDES, E. A. de M.; OLIVEIRA, P. M.; BENN-IBLER, V. (Orgs.). O novo milênio: interfaces lingüísticas e literárias. Belo Horizonte: Fale/UFMG, 2001.

; LINHARES, P. T. F. S. O preço da passagem no discurso de uma empresa de ônibus. In: MACHADO, I. L. (Org.). Análises de discursos: sedução e persuasão. Belo Horizonte: NAPq Fale/UFMG, 1993. (Caderno de Pesquisa n. 13).

FERNÁNDEZ, Z. Formas de privatización de empresas. Revista Economistas, n. 63, p. 2130, 1995.

FIORIN, J. L. Linguagem e ideologia. 7. ed. São Paulo: Ática, 2001.

FOUCAULT, M. Arqueologia do saber. Petrópolis: Vozes, 1972.

GAMSON, W. Talking politics. New York: Cambridge University Press, 1992.

GONZÁLEZ, A. M. Psicología comunitaria. Fundamentos y aplicaciones. Madrid: Editorial Síntesis, 1998.

GRANT, D.; OSWICK, C. Introduction: getting the measure of metaphors. In:

(Orgs.). Metaphor and organizations. London: Sage, 1996a. 
Metaphor and organization: issues and directions. In:

(Org.). Metaphor and organizations. London: Sage, 1996b.

GRAU, E.; IBARRA, P. (Coords.). Anuario de movimientos sociales: participando en la red. Barcelona: Icaria Editorial, 2001.

GREIMAS, A.; COURTÉS, J. Dicionário de semiótica. São Paulo: Cultrix, 1979.

JAKOBSON, R. Lingüística e comunicação. São Paulo: Contexto, 1988.

KLANDERMANS, B.; WEERD, M. de. Group identification and political protest. In: STRYKER, S.; OWENS, T.; WHITE, R. Self, identity, and social movements. Minneapolis: University of Minnesota Press, 2000.

MADRUGA, J. A. G.; RÍOS, S. M. Conceptos fundamentales de psicología. Madrid: Alianza Editorial, 1998.

MELUCCI, A. The process of collective identity. In: JOHNSTON, H.; KLANDERMANS, B. (Eds.). Social movements and culture. Londres: UCL Press, 1995. Vozes, 2001.

A invenção do presente: movimentos sociais nas sociedades complexas. Petrópolis:

MUMBY, D. K.; STOHL, C. Power and discourse in organization studies: absence and the dialetic of control. Discourse \& Society, London, v. 3, p. 313-332, 1991.

OLIVA, E. de C. Siderúrgicas - reflexos da privatização da gestão de recursos humanos. In: ENCONTRO ANUAL DA ANPAD, 24., 2000, Florianópolis. Anais... Rio de Janeiro: Anpad, 2000 .

PÁRAMO, J. M. G. Privatização e eficiência: é irrelevante a titularidade? Revista Economistas, n. 63, p. 32-43, 1995.

SÁNCHEZ, E. Definición de participación. Todos con la "esperanza". Continuidad de la participación comunitaria. Venezuela: Gaudy Contreras, 2000.

SANDOVAL, A. M. S. Algumas reflexões sobre cidadania e formação de consciência política no Brasil. In: SPINK, M. J. (Org.). A cidadania em construção: uma reflexão transdisciplinar São Paulo: Cortez, 1994.

The crisis of the Brazilian labor movement and the emergence of alternative forms of working-class contention in the 1990s. Revista Psicologia Política, São Paulo, v. 1, n. 1, p. 173-195, 2001.

STRYKER, S.; OWENS, T.; WHITE, R. Self, identity, and social movements. Minneapolis: University of Minnesota Press, 2000.

TOLFO, S. R. et al. A privatização e os impactos sobre o trabalho dos sujeitos de uma empresa de telecomunicações. In: ENCONTRO NACIONAL DA ABRAPSO, 11., 2001, Florianópolis. Anais... Florianópolis: Abrapso, 2001. 
WATSON, T. J. Rhetoric, discourse and argument in organizational sense making: a reflexive tale. Organization Studies, Berlin, v. 5, p. 805-821, 1995.

WESTWOOD, R.; LINSTEAD, S. Language/organization: Introduction. In: WESTWOOD, R.; LINSTEAD, S. The language of organization. London: Sage, 2001.

WETZEL, U. Transformação do contrato psicológico no contexto da privatização: estudo de casos. In: ENCONTRO DE ESTUDOS ORGANIZACIONAIS, 1., 2000, Curitiba. Anais... Rio de Janeiro: Anpad, 2000.

ZANOTTO, M. S. T. Metáfora e indeterminação: abrindo a caixa de Pandora. In: PAIVA, V. L. M. de O. (Org.). Metáforas do cotidiano. Belo Horizonte: NAD, 1998. 